\title{
Dynamic Allocation of Products to Storage Areas in the Warehouse
}

\author{
Hajira BAKKALI \\ Abdellah AZMANI \\ Abdelhadi FENNAN \\ Laboratory of Sciences Computer, Systems and Telecommunication (LIST) \\ Faculty of Science and Technology (FST) \\ University of Abdelmalek Essaadi Tangier, Morocco
}

\begin{abstract}
The warehouse is one of the major links in the supply chain; it plays a vital role in improving corporate profitability. Indeed, the performance management of logistics platforms depends on the optimal organization of different areas and flows there existing. In this context, the following paper proposes a method of warehouse spatial planning taking into account various constraints. The proposed method treats on one hand the optimal organization of different areas of the warehouse, on another hand, the allocation of products to storage areas.
\end{abstract}

\section{General Terms}

Logistics, Decision support, Artificial Intelligence.

\section{Keywords}

Warehouse, Dynamic Storage, Constraints, Optimization.

\section{INTRODUCTION}

Improving warehouse management is a major challenge for all companies. In fact, optimizing this management [1] brings significant gains for companies, mainly the profitability increasing and customer satisfaction. In order to meet these requirements; this work proposes a flexible and reactive organization method which enables adaptation to market demand fluctuations. This paper deals this problematic in two parts: the first part is devoted to analyzing the existing literature on different methods and technology used to allocate products to storage areas. The second part describes different stages of our proposed method to develop an equation that can help to optimize locations into storage areas.

\section{STATE OF THE ART}

\subsection{Organization of the Warehouse}

In the literature, there are several research works which treat the problem warehouses organization. Most of these works are concerned with the following issues:

- Physical organization: this problem concerns the internal organization of the warehouse according to different areas and existing flows. Authors of paper [2] deal the problem of sizing and the optimal physical structure according to various criteria.

- Planning and scheduling picking: several methods have been proposed to address this problem; paper [3] proposes algorithms to solve the optimization problem of picking touring.

- Products assignment to storage areas: this issue concerns the organization of products in storage areas to reach an optimal use of space and to minimize products recovery time.

This paper is interested in the latest issue mentioned. According to [4] [5], we can distinguish three policies for allocating products to storage areas:
- Random Storage: each product will be stored anywhere in the storage area.

- $\quad$ Dedicated storage [6]: each product will be assigned to a specific location.

- Storage based on the classification of products [6]: each product will be stored according to its order rate.

For dedicated storage, if the product is not available in the warehouse, then the location will be empty and there will be loss of space. Whereas, for random storage, the same product can be found at different locations and therefore that causes a loss of time to search and retrieve products.

As a conclusion, according to the chosen policy there will be a waste of space that will be offset by a gain in time or the reverse.

\subsection{Methods and Techniques:}

This section covers the various existing methods and techniques to solve the problem:

- Dynamic Stock Location Assignment Algorithm (SLAA) is a dynamic algorithm that allows to associate incoming products to locations in storage areas in order to optimize products handling costs and improve the use of space. Sadiq and al [8] use this algorithm for a system of order picking.

- The Cube Per Order Index (CPOI): The rule of the Cube Per Order Index CPOI was developed by Heskett (1963.1964). The basic rule is that the most commonly used products must be placed strategically and the least useful products must be stored at predefined locations. Gu and al. [9] decry it has been proved that the optimal policy is CPOI by minimizing handling products.

- $\quad$ Automated Storage and Retrieval Systems:(AS/ RS) These are systems of storage and automated recovery, they are usually used in the distribution as well as in production environments. Roodbergen and screws [10] present a literary review on the

AS / RS

- Forward Reserve Problem (FRP): The objective of the FRP is to provide a heuristic for assigning products in a storage area in order to reduce the cost of picking; however it increases the cost of reconstruction. The challenge is to look for products that must be stored in one place and in what quantity. Hackman et al. (1990) were the first who 
have presented a model for FRP which considers both the allocation and distribution of products.

\section{PROPOSED METHOD}

To study the problem of assigning products to storage areas, we propose to follow the steps below:

- Identifications of different areas of the warehouse.

- Identification of storage area obstacles.

- Determination of the actual volume of the storage area.

- Modular organization of storage areas.

- Identification of storage constraints.

- Creating decision trees for different states of the zone.

These steps enable finally to develop an algorithm to optimize locations taking into account various storage constraints.

\subsection{Identification of Areas of the Warehouse}

The warehouse is a geographic zone divided into several areas. The number of these areas differs from one warehouse to another depending on the type of activity and the types of products that will transit inside [10][11]. We can classify these areas following three categories: functional areas[12], technical areas, and related areas.

\section{- Functional Areas}

It is from these areas, that we can perform the following operations: receiving, storing, preparing and delivering goods [13] [14].

Table 1. Description of the functional areas

\begin{tabular}{|l|l|}
\hline Reception area & Control of incoming goods area. \\
\hline Storage area & $\begin{array}{l}\text { Storage of goods including the aisles and } \\
\text { locations identified area. }\end{array}$ \\
\hline Delivery zone & $\begin{array}{l}\text { Shipment or delivery of customer orders } \\
\text { area. }\end{array}$ \\
\hline Preparation area & Sorting and primary packaging area. \\
\hline $\begin{array}{l}\text { Administrative } \\
\text { Area }\end{array}$ & This area is reserved for office space. \\
\hline
\end{tabular}

- Technical areas

These are areas reserved for the technical rooms [15]:

Table 2. Description of the technical areas

\begin{tabular}{|l|l|}
\hline $\begin{array}{l}\text { Maintenance } \\
\text { Workshop }\end{array}$ & $\begin{array}{l}\text { Reserved for the maintenance of } \\
\text { materials and equipment in the } \\
\text { warehouse area }\end{array}$ \\
\hline Electric Local & $\begin{array}{l}\text { Reserved place holder for power } \\
\text { distribution. }\end{array}$ \\
\hline Battery charging & $\begin{array}{l}\text { Reserve for battery chargers for electric } \\
\text { trucks. }\end{array}$ \\
\hline Local security & $\begin{array}{l}\text { Reserved for safety equipment } \\
\text { (compressors). }\end{array}$ \\
\hline $\begin{array}{l}\text { compactor and } \\
\text { empty } \\
\text { packaging }\end{array}$ & $\begin{array}{l}\text { Reserved for packing and compaction of } \\
\text { waste. }\end{array}$ \\
\hline
\end{tabular}

- Annexes areas

The warehouse design requires related areas to perform certain functions:
Table 3. Description of the annexes areas

\begin{tabular}{|l|l|}
\hline Sanitary facilities & Changing rooms, toilets, shower ... \\
\hline Local social & Kitchen, restroom, local to syndicate \\
\hline
\end{tabular}

\subsection{Identification of Obstacles Storage} Areas

In the warehouse, there may be areas that present obstacles in storage where goods cannot be stored. The identification of these barriers has led us to the following classification:

- Structural areas: it is the space occupied by poles, columns, above obstructions (lamps, pipes, and beams), intermediate walls, toilets and other building structures.

- Unusable areas: these are areas that represent anomalies (flooded area, oil flow,), which cause a slowing of operation and a schedule delay.

- Functional areas reserved for the office areas, circulation aisles, reception areas, preparation and shipping.

- Constraints areas: these are areas lost due to storage constraints such as the nature of the product requires to leave an empty space between incompatible products; product weight defines the maximum storage height.

\subsection{Determination of Real Storage Volume}

\subsubsection{Volume zone}

To determine the real volume of a storage area, it is first necessary to calculate the following variables:

- the theoretical volume of the zone $\mathrm{k}$ :

$$
-\mathrm{V}_{\mathrm{T}}\left(\mathrm{Z}_{\mathrm{k}}\right)=\mathrm{L}_{\mathrm{k}} * \mathrm{l}_{\mathrm{k}} * \mathrm{H}_{\mathrm{k}}
$$

With $\left(L_{k}\right)$ the length of the area, $\left(l_{k}\right)$ is the width of the area, and $\left(\mathrm{H}_{\mathrm{k}}\right)$ is the height of the area.

- The volume of the structural loss 1 :

$$
\mathrm{V}_{\mathrm{s}}\left(\mathrm{Z}_{\mathrm{k}}\right)=\sum_{\mathrm{i}=1}^{\mathrm{n} 1} \mathrm{~V}_{\mathrm{T}}(\mathrm{i})
$$

With $\mathrm{n} 1$ is the number of areas which represent the structural loss in zone $\mathrm{k}$.

- volume abnormalities zones:

$$
\mathrm{V}_{\mathrm{a}}\left(\mathrm{Z}_{\mathrm{k}}\right)=\sum_{\mathrm{i}=1}^{\mathrm{n} 2} \mathrm{~V}_{\mathrm{T}}(\mathrm{i})
$$

With $\mathrm{n} 2$ is the number of defect areas in the zone $\mathrm{k}$. - volume of functional areas:

$$
\mathrm{V}_{\mathrm{f}}\left(\mathrm{Z}_{\mathrm{k}}\right)=\sum_{\mathrm{i}=1}^{\mathrm{n} 3} \mathrm{~V}_{\mathrm{T}}(\mathrm{i})
$$

With $\mathrm{n} 3$ is the number of functional areas in the zone $\mathrm{k}$. - The lost volume

$$
\mathrm{V}_{\mathrm{c}}\left(\mathrm{Z}_{\mathrm{k}}\right)=\sum_{\mathrm{i}=1}^{\mathrm{n} 4} \mathrm{~V}_{\mathrm{T}}(\mathrm{i})
$$

With $\mathrm{n} 4$ is the number of constraints in the storage zone $\mathrm{k}$ areas.

According to the literature, the calculation of the actual volume is defined by the following expression [16]: 


$$
\mathrm{V}_{\mathrm{R}}\left(\mathrm{Z}_{\mathrm{k}}\right)=\mathrm{V}_{\mathrm{T}}\left(\mathrm{Z}_{\mathrm{k}}\right)-\left(\mathrm{V}_{\mathrm{s}}\left(\mathrm{Z}_{\mathrm{k}}\right)+\mathrm{V}_{\mathrm{f}}\left(\mathrm{Z}_{\mathrm{k}}\right)\right)
$$

Taking into account the volumes and the formula becomes:

$$
\begin{gathered}
\mathrm{V}_{\mathrm{R}}\left(\mathrm{Z}_{\mathrm{k}}\right)=\mathrm{V}_{\mathrm{T}}\left(\mathrm{Z}_{\mathrm{k}}\right)-\left(\mathrm{V}_{\mathrm{s}}\left(\mathrm{Z}_{\mathrm{k}}\right)+\mathrm{V}_{\mathrm{f}}\left(\mathrm{Z}_{\mathrm{k}}\right)+\mathrm{V}_{\mathrm{a}}\left(\mathrm{Z}_{\mathrm{k}}\right)\right. \\
\left.+\mathrm{V}_{\mathrm{c}}\left(\mathrm{Z}_{\mathrm{k}}\right)\right) \\
\end{gathered}
$$

We put

$$
V_{P}\left(\mathrm{Z}_{\mathrm{k}}\right)=\mathrm{V}_{\mathrm{s}}\left(\mathrm{Z}_{\mathrm{k}}\right)+\mathrm{V}_{\mathrm{f}}\left(\mathrm{Z}_{\mathrm{k}}\right)+\mathrm{V}_{\mathrm{a}}\left(\mathrm{Z}_{\mathrm{k}}\right)+\mathrm{V}_{\mathrm{c}}\left(\mathrm{Z}_{\mathrm{k}}\right)
$$

The expression becomes:

$$
\mathrm{V}_{\mathrm{R}}\left(\mathrm{Z}_{\mathrm{k}}\right)=\mathrm{V}_{\mathrm{T}}\left(\mathrm{Z}_{\mathrm{k}}\right)-\mathrm{V}_{\mathrm{P}}\left(\mathrm{Z}_{\mathrm{k}}\right)
$$

$\mathrm{V}_{\mathrm{R}}\left(\mathrm{Z}_{\mathrm{k}}\right)=\mathrm{V}_{\mathrm{T}}\left(\mathrm{Z}_{\mathrm{k}}\right)-\sum_{\mathrm{i}=1}^{\mathrm{n}} \mathrm{V}_{\mathrm{T}}(\mathrm{i})$, Where $\mathrm{n}$ is the total

number of obstacles storage areas.

\subsubsection{Determination of storage volume for a warehouse}

A warehouse is defined by a set of areas, while the total useful volume for storage is:

$$
V u(E)=\sum_{k=1}^{n} \mathrm{~V}_{\mathrm{R}}\left(\mathrm{Z}_{\mathrm{k}}\right), \mathrm{n} \text { is number of areas }
$$

Substituting expression $\mathrm{V}_{\mathrm{R}}\left(\mathrm{Z}_{\mathrm{k}}\right)$ defined above, we obtain

$$
V u(E)=\sum_{k=1}^{n}\left(\mathrm{~V}_{\mathrm{T}}\left(\mathrm{Z}_{\mathrm{k}}\right)-\sum_{i=1}^{n 1} \mathrm{~V}_{\mathrm{T}}\left(Z_{k i}\right)\right)
$$

This first result shows that to increase the useful volume of storage in a warehouse, we need to minimize the volumes of obstacles:

$$
\operatorname{Min}\left(\sum_{i=1}^{n 1} \mathrm{~V}_{\mathrm{T}}\left(Z_{k i}\right)\right)
$$

From this result, it can be concluded that organizational models of areas must respond to this objective (decrease lost volumes).

\subsection{Modular Organization}

The modular organization of the storage area allows maximum utilization of the surface. Indeed, depending on the types of products that pass through the warehouse [17], this paper proposes to divide the area into two areas: flexible zones and stationary zones.

\subsubsection{Flexibles zones}

These are areas that can be adapted to the new constraints:

- Fusion of two areas with the same product.

- Fusion of multiple zones with different products.

- Creation of a new area with different products.

\subsubsection{Stationary zones}

These are areas which include products that have special properties:

- Needs of specific provisions: products must remain in cold areas.

- Products with rigid constraints: products must be stored in specific areas.

- Dangerous products: Aerosols, dangerous, flammable liquids.
The modular organization of the storage area with a maximization of flexible areas and minimizing fixed areas, achieves an optimal space use and an adaptation with the demand predictions.

\subsection{Allocation of Goods to Storage Areas}

3.5.1 Identification of constraints:

Assigning a product to an area depends on various constraints:

- Goods are obligatorily assigned to a specific area:

- Preparation constraint: If the product needs preparation so it will be assigned to the preparation area.

- Temporary constraint: there are products that require temporary storage before being shipped or stored, so it must be assigned to a temporary area.

- Goods should preferably be assigned to a specific area.

- Goods must avoid certain environmental conditions : humidity, heat, dusts and sunlight

- Goods should preferably avoid certain environmental conditions: goods have a sensitivity to low humidity, dust,etc.

- Goods must be placed near the exit

- Rotation constraint: Products with a high rotation rate are placed close to the exit to minimize access time.

- Goods must be placed distant from each other.

- Compatibility constraint: there are products having incompatibilities [18]. They need to be stored far enough from the others (flammable and oxidizing products).

- Constraints owners of rigid goods

- Compact Volume: inseparable volume.

- Constraint superposition:

$\checkmark \quad$ A heavy product cannot be placed on a light one.

$\checkmark$ The packaging does not allow to goods, or goods block , a commodity to be on another product.

$\checkmark \quad$ The packaging does not allow to goods, or goods block, a commodity receive another product.

- Constraints owners to flexible goods

- Handy volume: volume separable.

- Absence of superposition constraints.

\subsubsection{Representation of the assignment problem} as decision tree:

After observing the different scenarios, it becomes able to develop three trees depending on the state of the area:

- Filled area: in this case occupancy rate is To $=100 \%$. (Fig.5)

- Empty area: in this case occupancy rate is $\mathrm{To}=0 \%$. (Fig.2)

- One part of area is empty: in this case, we compare the available volume of the zone with the volume of the goods, we obtain two possibilities

- Available volume is less than the goods volume $(\mathrm{Vd}<\mathrm{Vm})$ (Fig.4)

- Available volume is greater than or equal to goods volume $(\mathrm{Vd}>=\mathrm{Vm})($ Fig.3) 


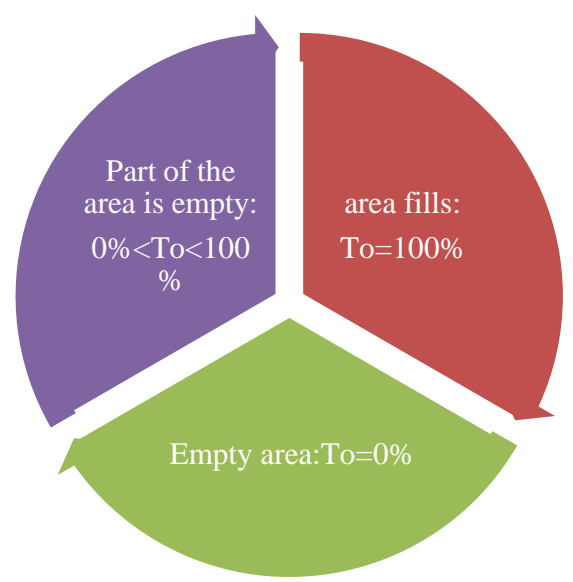

Fig.2: States of storage area

\subsection{Analysis of results:}

The route paths of these trees eventually generate two results: either the volume is stored, or it is rejected. The analysis of these different paths shows four decisions: direct storage, provisional storage in a temporary area, storage in another warehouse, and liberation of an area to do the transfer. Choosing the best decision depends on determining the conditions to be met: time constraints or space constraints.

If we choose to satisfy time constraints, the two following solutions must be removed: storage in another warehouse and liberation of a zone for the transfer.

To solve this problem, we propose to apply the constrained optimization algorithms such as genetic algorithms, the algorithm Max Min.

\subsection{Algorithm proposed}

Algorithm for assigning goods to storage areas

The input variables:
$\mathrm{N}$ : number of the storage volume in the zone $\mathrm{Z}$

$\mathrm{Vj}$ : storage volumes of the zone $\mathrm{Z}$

Vm: Volume Goods

For $\mathrm{j}=1$ to $\mathrm{N}$ do

If $($ Volume $(\mathrm{Vj})>=\mathrm{Vm})$

Then If (satisfaction constraint $(\mathrm{Vj})=1$ )

Then If $($ state $(\mathrm{vj})=$ free $)$

Stocker (Vm);

Else release area $(\mathrm{Vi})$;

end if

else if Transfer $(\mathrm{Vm})$;

end if

ELSE if $($ type $(v m)=$ compact $)$

Division (Vm);

Else Waiting output ();

end if

end if.

\section{CONCLUSION AND PERSPECTIVES}

This paper proposes a management approach of the storage areas taking into account the different obstacles:

- $\quad$ The structural loss;

- Areas with anomalies not usable temporarily;

- Constraint storage.

It is the first level of spatial organization that directed us to some interesting perspectives on the following areas:

- Optimization of locations using intelligent planning.

- Managing goods flows: inflows and outflows.

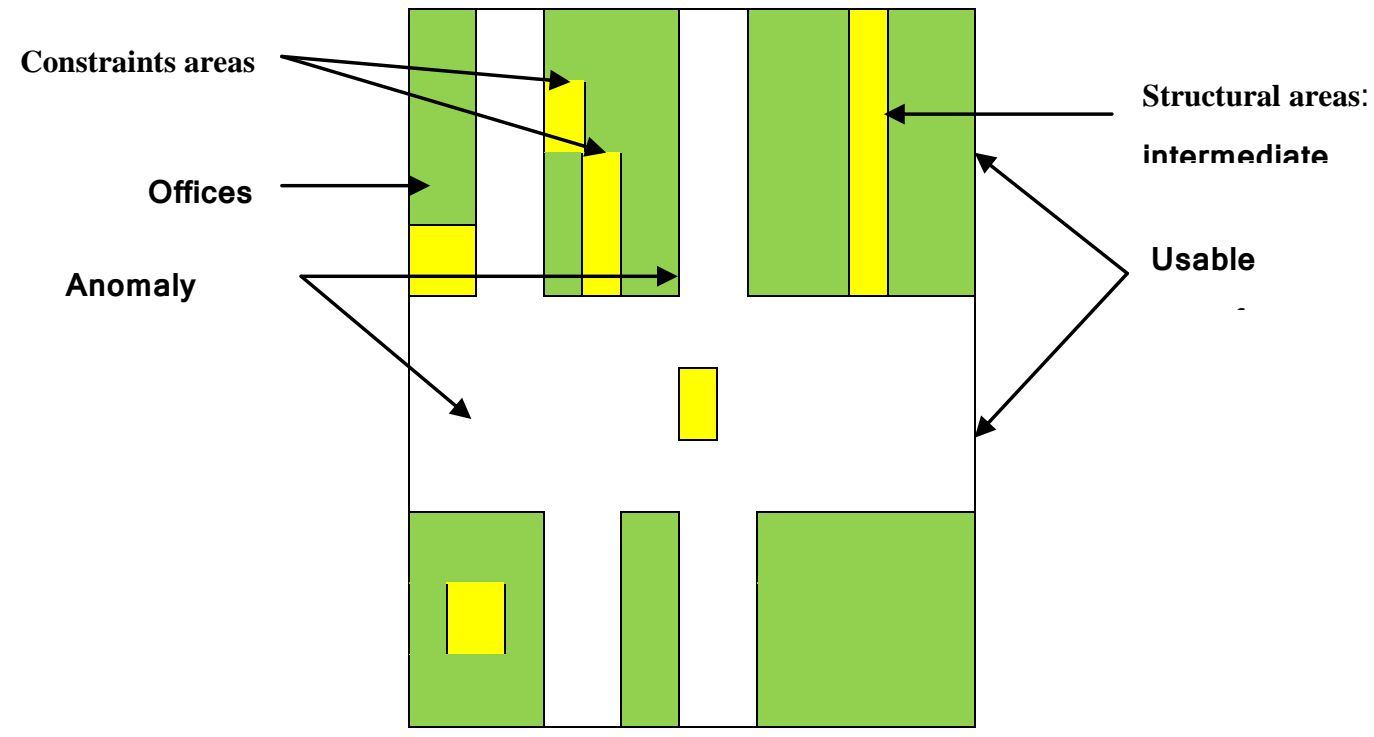

Fig 1: Presentation of obstacles storage areas 


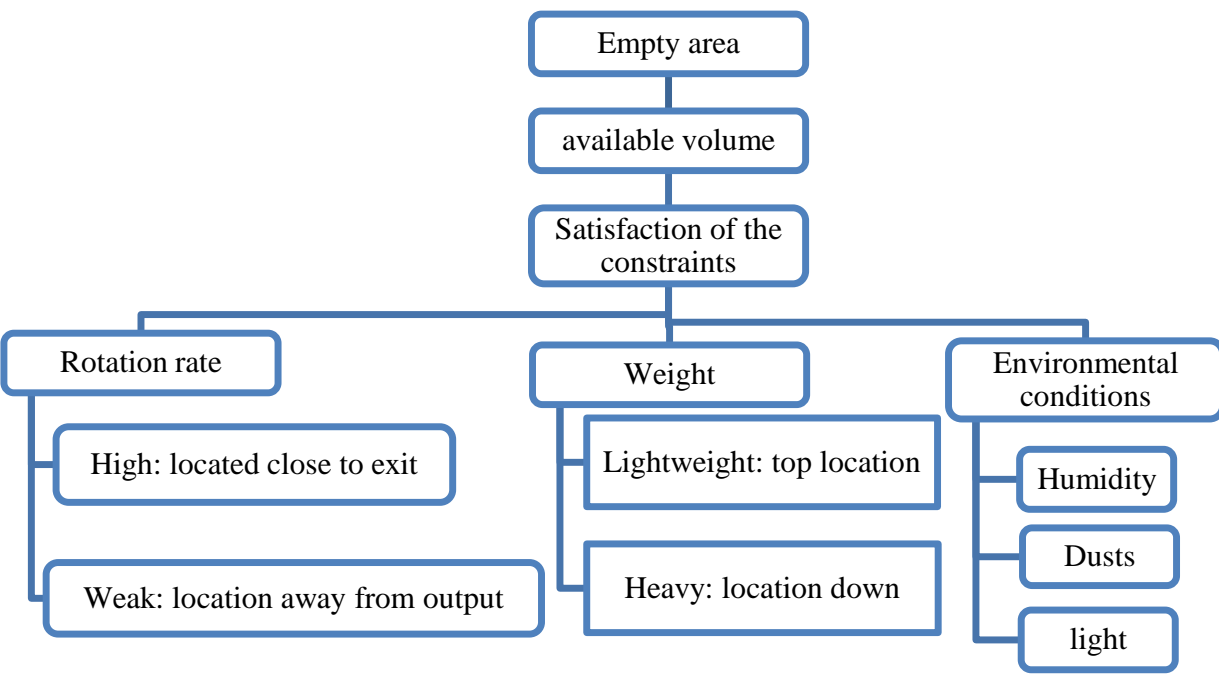

Fig 2: Allocation in the case of empty

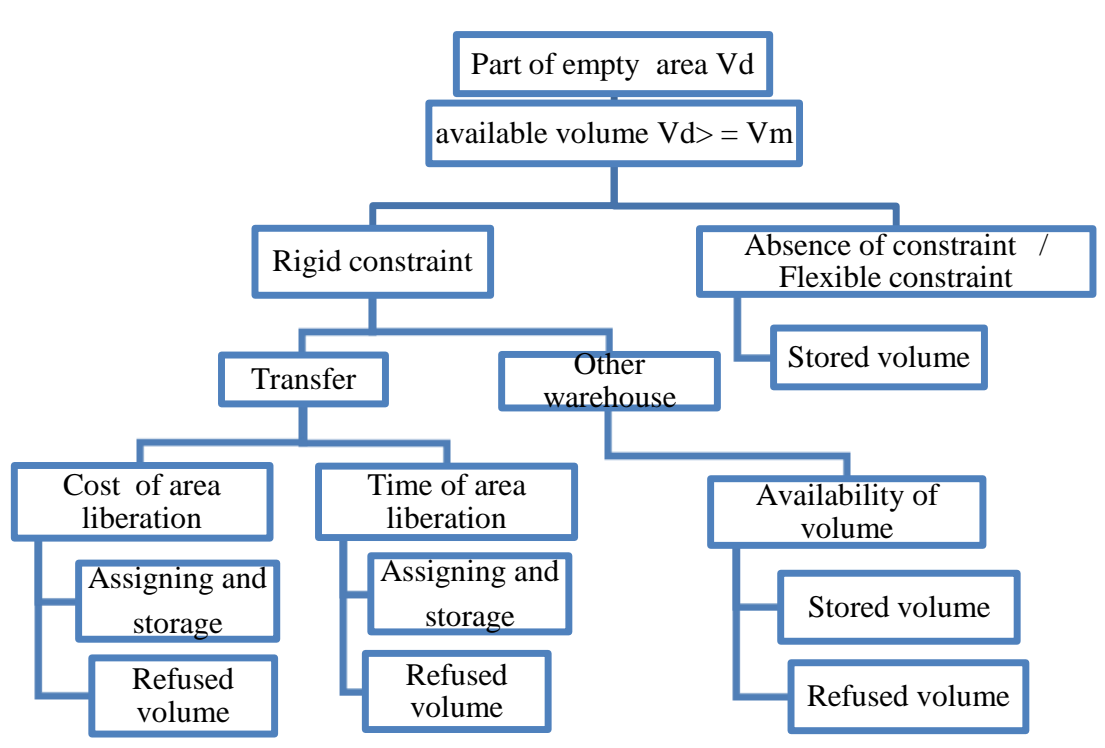

Process area

Fig 3 : Allocation Process in the case of part of empty area (Vd $>=\mathrm{Vm})$ 


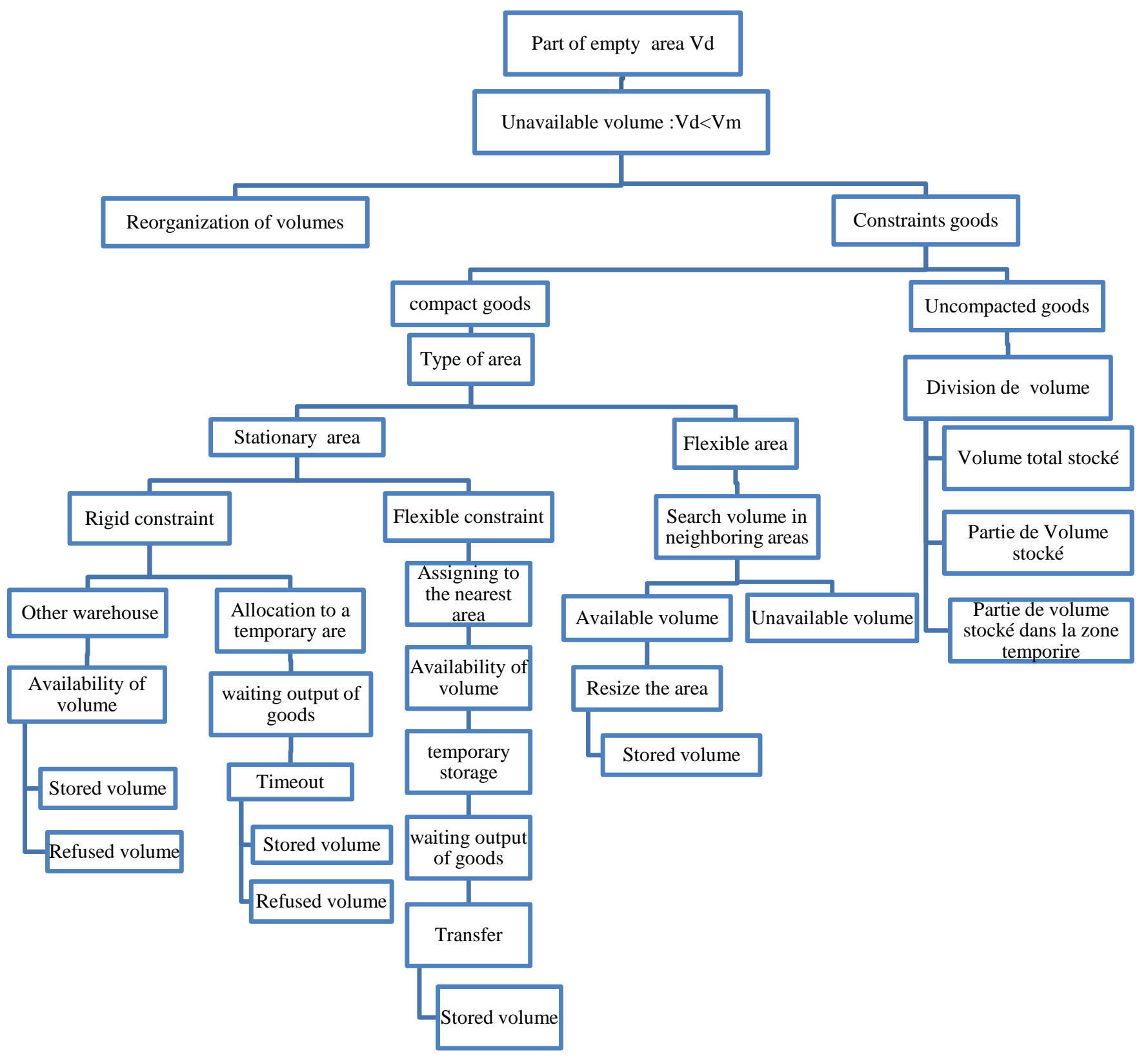

Fig 4: Allocation Process in the case of part of empty area $(\mathrm{Vd}<\mathrm{Vm})$ 


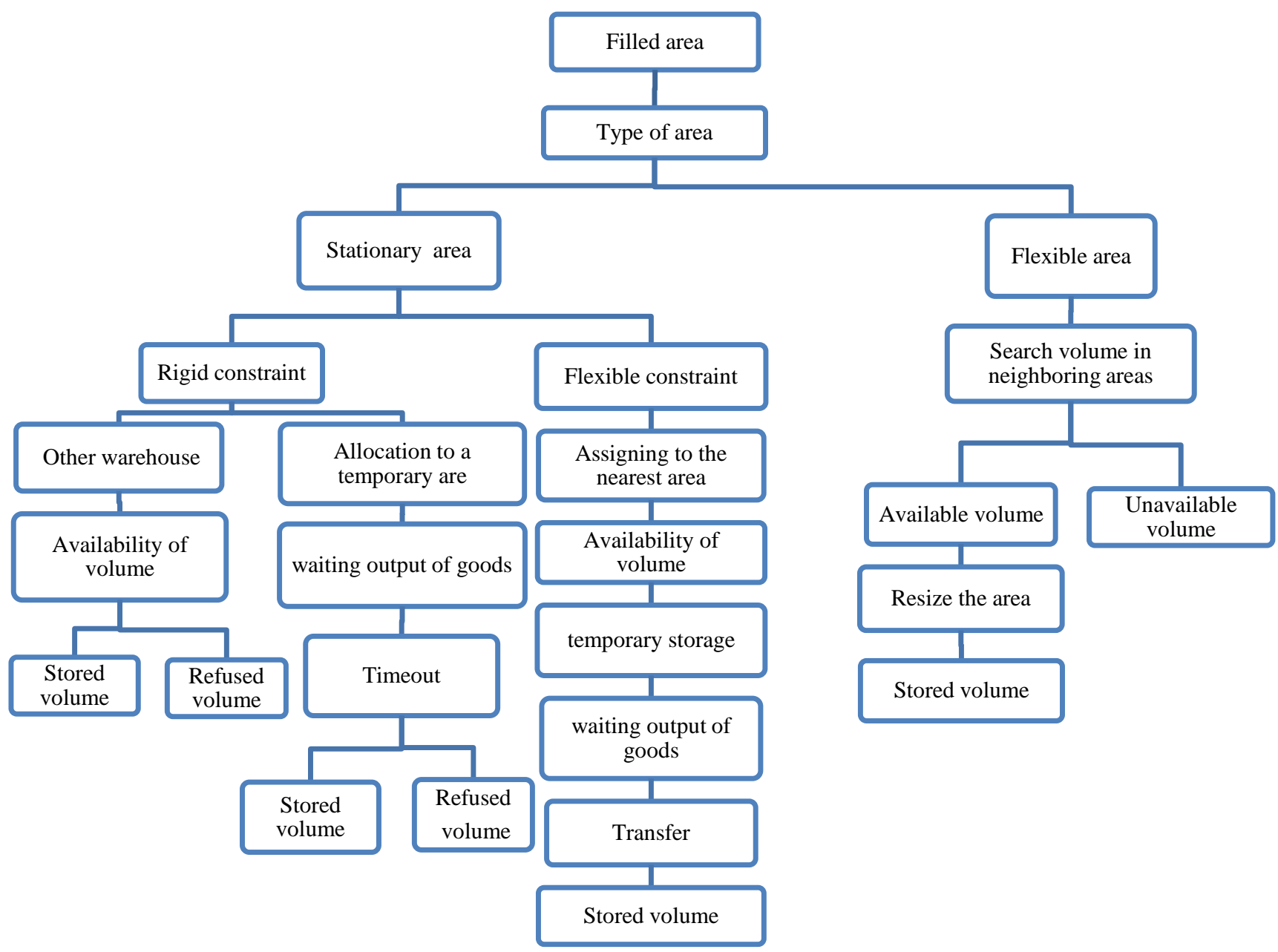

Fig 5: Allocation Process in the case of a filled area

\section{REFERENCES}

[1] G.Ghiani, G.Laporte and R. Musmanno 2004 .Introduction to Logistics Systems Planning and Control.

[2] S.S. Heragu, L. Du, R.J. Mantel et P.C. Shuur : Mathematical model for warehouse design and product allocation. International Journal of Production Research, 43(2):327-338, 2005

[3] R. de Koster, T. Le-Duc et K. J. Roodbergen : Design and control of warehouse order picking : a literature review. European Journal of Operational Research, 182:481-501, 2007

[4] J. P. van den Berg : A literature survey on planning and control of warehousing systems. IIE Transactions, 31:751-762, 1999.

[5] Roodbergen, K. J. (2005). Storage assignment policies for warehouses with multiple cross aisles, In: Meller et al. (eds.) Progress in Material Handling Research: 2004, pp. 541-560.
[6] Petersen, C.G., Aase, G. and Heiser, D.R. (2004). Improving order-picking performance through the implementation of class-based storage. International Journal of Physical and Logistics Management 34(7), 534-544

[7] M. Sadiq, T. L. Landers, and G. Don Taylor: An assignment algorithm for dynamic picking systems, p607:616 - 1996

[8] Jinxiang Gu, Marc Goetschalckx \& Leon F. McGinnis: Research on warehouse operation: A comprehensive review. European journal of operational research 1:212007

[9] Kees Jan Roodbergen, Iris F. A. Vis: A survey of literature on automated storage and retrieval systems, p343:362 - 2009

[10] F. Mocellin : Gestion des entrepôts et plates-formes. Dunod, Paris, France, 2006.

[11] Michel Roux : Tout ce qu'il faut savoir pour concevoir une unité de stockage, 4e édition, Groupe Eyrolles,2008 
[12] Mathieu Coraze : Les bases de la gestion logistique au sein d'un entrepôt, 2003.

[13] H. Bakkali, A.Azmani, and A. Fennan.2013. Modeling of the Physical Flow of Goods within the Warehouse by the Hierarchical Coloured Petri Nets. International Journal of Advanced Research in Computer Science and Software Engineering, Issue 9,Vol.3

[14] H.Bakkali, A.Azmani and A.Fennan.2013. Identification of the parameters considered in the warehouse management and modeling its physical flow of goods, in proceeding of the 6th International Symposium LOGISTIQUA
[15] Yves Pimor Michel Fender., LOGISTIQUE : Production Distribution Soutien, 5e édition, Dunod, 2008.

[16] Organisation Panaméricaine de la Santé : Logistique et gestion des approvisionnements du secteur santé Washington, D.C., 2003

[17] H.Bakkali, A.Azmani and A.Fennan.2012 .Modular Organization of warehouse, in proceeding of international conference on business intelligence and technology

[18] H.Bakkali, S.Khali issa and A.Azmani and.2013. The modeling of fire hazards in a goods warehouse by the Bayesian network. Issue 3, Vol.2. 